\title{
Impact of incentive driven medical home approach on use of preventive services use among healthcare system employees: A case study
}

\author{
Sandra E. Brooks ${ }^{* 1}$, Yehia H. Khalii ${ }^{2}$, Allison M. Ledford ${ }^{2}$, Tina M. Hembree ${ }^{2}$ \\ ${ }^{1}$ CompleteCare Health Network, Bridgeton, New Jersey, United States \\ ${ }^{2}$ Norton Healthcare, Louisville, Kentucky, United States
}

Received: July 23, 2015

DOI: $10.5430 /$ jha.v5n1p1
Accepted: September 14, $2015 \quad$ Online Published: October 12, 2015

URL: http://dx.doi.org/10.5430/jha.v5n1p1

\begin{abstract}
Objective: To describe the initial outcomes of an incentive driven medical home and navigation program on preventive services among healthcare system employees.

Methods: Quasi-experimental design examining participation, use of preventive services and adherence to medical guidelines and emergency room use in a five hospital integrated health system. Employees were required to complete a health risk assessment (HRA), visit a Primary Care Provider (PCP) and submit PCP visit screening and biometric results in order to be eligible for the financial incentives. Subsidized lifestyle change intervention and navigation programs were also offered to participants. Descriptive statistics and Chi Square were used to analyze results for the 5,435 employee participants and 3,623 non-participants during thee 1-year intervention.

Results: Preventive care visits for participants increased by 35\% compared to an increase of 3\% for non-participants. Nonadherence to medical guidelines decreased $7 \%$ for participants and increased $18 \%$ for non-participants. Inappropriate emergency room use overall decreased from $20 \%$ to $14 \%$.

Conclusions: One year after introduction of the wellness program, preventive visits increased, compliance with medical care increased and inappropriate emergency room visits were reduced.
\end{abstract}

Key Words: Worksite wellness, Population health, Medical home

\section{INTRODUCTION}

It is estimated that $75 \%$ of healthcare dollars are spent treating preventable chronic conditions. ${ }^{[1]}$ The CDC: Power of Prevention 2009 report indicated that successful wellness initiatives including education, social support, and supportive policies have the potential to promote population health. ${ }^{[2]}$ Although there is a potential to reach large segments of the population through worksite wellness programs, the potential of these programs has not yet been fully realized. As employers focus on population health management, long term investments in transforming organizational culture are vital to improvement in health and health outcomes for employees.

A review of worksite wellness programs published by Osilla et al. revealed mixed results Regarding the impact of the programs on health related behaviors, substance use, physiologic markers, and cost. ${ }^{[3]}$ The authors cited the lack of

\footnotetext{
* Correspondence: Sandra E. Brooks, MD, MBA; Email: sandraebrooks40@aol.com; Address: CompleteCare Health Network, 53 S. Laurel Street, $2^{\text {nd }}$ Floor, Bridgeton, NJ 08302, United States.
} 
rigorous evaluation designs and noted a paucity of research in stark contrast to the widespread use of such programs. The need for further investigation was also highlighted by Mattke et al. of the Rand Corporation. ${ }^{[4]}$

Recognizing the potential importance of employee wellness programs in promoting population health, the Affordable Care Act (ACA) includes provisions for employers to now use up to $30 \%$ of the total amount of employees' health insurance premiums $(50 \%$ at the discretion of the secretary of health and human services) to provide outcome-based wellness incentives. ${ }^{[5]}$ Such rewards can be in the form of a discount or rebate of a premium or contribution, a waiver of all or part of a cost-sharing mechanism such as deductibles, copayments. The hope behind this ACA provision is that it will improve health-related behavior and reduce the prevalence of chronic disease caused by unhealthy lifestyles. The effectiveness of incentive programs depends critically on how the incentives are timed, distributed, and framed and other approaches may be required to achieve optimal results. ${ }^{[6,7]}$

Given the important role employee wellness have for future population health initiatives, in this report, we describe the first year impact of an incentive driven worksite wellness program incorporating encouragement of medical homes and navigation on preventive services among community based healthcare system employees.

\section{Methods}

\subsection{Design}

We performed an observational study and preliminary program evaluation to assess outcomes associated with implementation of a voluntary wellness plan for employees of a large health system. An Institutional Review Board (IRB) exemption was granted for this study by the University of Louisville IRB, health assessment data was stripped of identifiers and analyzed in aggregate only. Secondary analyses were performed on de-identified claims data.

Participation was defined as completion of an on line health risk assessment (HRA) and a wellness visit with the employee's primary care physician. Health history and biometric data were captured in a Health Insurance Portability and Accountability Act (HIPAA) compliant environment, entered into a database. Participants who completed the required elements received payroll credits. Employees with risk factors for chronic disease (such as diabetes, hypertension, obesity, and tobacco use) to work with nurse navigators and health educators to assist them in enrolling in programs designed to reduce their risk of adverse health outcomes. Impact was measured through rates of participation, number of employees receiving preventive care visits, number of patients navigated to follow up. Those that opted out of enrolling in the program were able to access all services but were not eligible to obtain payroll "wellness" credits. Outcomes were measured through medical claims assessment of adherence to medical guidelines using the Care Gap Index (CGI) measure of compliance with medical standards per condition and percentage of inappropriate emergency room visits (non-urgent or minor issues). ${ }^{[7]}$

\subsection{Sample}

The setting and eligible population included employees of a five hospital integrated, self-insured, health system, with 12 immediate care centers and more than 100 physician practice locations in Louisville, KY. A total of 9,058 employees were eligible for participation during the period 2011-2012. Eighty-two percent of employees were female and $18 \%$ were male. Baseline and follow-up data were aggregated from medical claims $(5,435$ participant and 3,623 non-participants).

\subsection{Measures}

Subject variables included: age, gender, health status and outcome variables included participation rates, navigation, preventive care use, generic drug use, and emergency room uses. Data was obtained from the following sources:

(1) A National Committee for Quality Assurance (NCQA) certified online HRA

NCQA certified online HRA helped the employee and the wellness program team to understand employee health needs, risks and overall health. Employees electronically signed consent to allow navigators on the employee wellness team to interact with them based on findings on the HRA and primary care visit. All information is HIPAA protected and cannot be used to make employment decisions.

(2) Verified Biometric and laboratory data

Employees were asked to see their primary care physician for an annual wellness visit and to submit specific biometric and laboratory data (e.g. blood pressure, body mass index, glucose) to be included in the employee wellness database as verification of the HRA and to verify eligibility to receive wellness credits for participation. Lifestyle intervention programs were available for employees with risk factors or previously established chronic diseases that were amenable to intervention such as diabetes or hypertension.

(3) Medical and pharmaceutical claims

Third party vender aggregate level medical and pharmaceutical claims for all employees average number of emergency room visits, screening and monitoring of 
established disease (e.g. HbA1C for individuals with diabetes).

(4) Employee demographics

Age, gender, occupation, and working facility location.

This study focus on the following variables:

(1) Participation rates:

During the process, participation rates for the HRA and the primary care visit was observed and aggregated by employee demographics such as age-groups, working shifts, and gender on a regular basis.

(2) Preventive care visits rates:

This measure reflected the percentage of employees who received any necessary recommended preventive care services (such as screening for breast cancer, diabetes, etc.) during the reporting year based on the medical claims data, which is aggregated by third party vender.

(3) Emergency services utilization:

Medical claims data were reviewed to evaluate the use of emergency services which could have been potentially been treated in another setting such as a medical home or urgent care center.

(4) CGI $^{[8]}$

The Healthcare Effectiveness Data and Information Set (HEDIS) is a comprehensive set of performance measures sponsored and maintained by the NCQA, the HEDIS consists of 75 measures across eight domains of care to evaluate/compare quality of provided care. A third party vender provided aggregate level summary for employees not receiving recommended health care services (with gaps in healthcare) as CGI. The CGI is utilized to monitor improvement in care provided and evaluate the impact of establishment of medical home. Examples of gaps in care would include, lack of claims for preventive services such as preventive visits, mammography services, or $\mathrm{HbA}_{1} \mathrm{C}$ testing in patients with a diagnosis of diabetes.

All data analyses and reporting were completed using SAS Guide 4.1 statistical software. ${ }^{[9]}$

\subsection{Intervention}

\subsubsection{Developing leadership support, infrastructure and communication}

We worked with system leaders to identify and support initiatives which would inspire and coordinate the needed changes to promote employee wellness. This included statements of support in public appearances, in written documents and in videos and rewards and recognition and system wide challenges. In addition, we advanced a healthy food policy for our facilities and catering including limiting availability of sugared beverages. Additional strategies included: print, electronic and in person communication and team challenges. These steps were essential to promoting behavior change and shaping a healthier work environment. ${ }^{[10,11]}$

The following interventions allowed us to overcome communication and logistics barriers: ${ }^{[12]}$

- Developed wellness champions embedded throughout the organization to expand capacity for communication and to lead best practices for health and wellness activities.

- Revised print and in person communications and training of leaders to support and promote wellness program initiatives in order that the rationale for the program was clear.

- Trained navigators to deliver interventions and inform employees of the personal benefits of the wellness program.

- Established of cross disciplinary work groups to develop interventions designed to promote wellness.

- Developed of mechanisms to address cross-cutting issues such as stress, injury, availability of nutritious food and work environment conditions.

- Intensive training of employee wellness staff to enhance level of knowledge and emphasize the importance of privacy. Limited access of protected health information.

- System-wide canvassing campaign to emphasize key components of program.

- Individual and mass communications to employees.

- Accumulation of a "frequently asked questions" list through informal interaction, telephone calls and electronic communication.

- Focus groups to gain feedback from employees.

- Web based access to forms and information on a dedicated website.

\subsubsection{Promotion of establishment a medical home and pa- tient navigation}

We utilized existing infrastructure to incentivize employees to establish a medical home. This strategy ensured comprehensive care, privacy, and long term follow up. To address barriers of communication and privacy we implemented the following:

- Work with system to expand appointment availability.

- Obtained consent from employee participants to contact for the purposes of navigation to health resources and information (an initial focus was placed on individuals who had identified risk factors for metabolic syndrome and those who utilized tobacco). 
- Education of practice administrators and front desk staff.

- Established a mechanism to connect employees with a primary care provider.

\subsubsection{Incentivize health screening, biometric tests and par- ticipation in disease management program}

- Employees were financially incentivized to complete their HRA, see their primary care physician, attest to completion of screening tests.

- Individuals who were considered at established or elevated risk for developing metabolic syndrome, tobacco users were contacted (with permission) and provided follow up and assistance.

\subsection{Analysis}

Baseline and follow up aggregate medical claims data (emergency room utilization, preventive care visits, generic prescriptions utilization and relative CGI) was collected for participants and non-participants for 2011 and 2012. In addition, we analyzed participant self-reported and data from primary care physicians collected for 2012.
Chi-Square test was utilized to test the independence of participation rates with factors such as gender, work shifts and age groups.

\section{RESUlts}

\subsection{Process evaluation}

During the study period, $6,794 / 9,058$ or $75 \%$ of eligible employees completed an online HRA and 2,264/9,058 or 25\% did not. Sixty percent $(5,435 / 9,058)$ completed both the HRA and visited their primary care physician and thus were eligible to receive the financial incentive and $40 \%(3,623 / 9,058)$ were not eligible to receive the incentive. Forty-three percent $(2,350 / 5,435)$ of those eligible were referred for disease management and 6\% $(137 / 2,350)$ participated in intervention programs.

A descriptive analysis and Chi-square test of the distribution of employees by working shifts, gender, average age and participation ratios across the organization revealed that males and individuals who worked at night were less likely to participate fully (see Table 1).

Table 1. Participation rates by gender, shifts and age groups

\begin{tabular}{lllll}
\hline & Varieties & Participant (n = 5,435) & Non-Participant (n = 3,623) & Chi Square $\boldsymbol{p}$-value \\
\hline \multirow{2}{*}{ By Gender } & Male & $841 / 5,435(16 \%)$ & $859 / 3,626(24 \%)$ & $p<.0001$ \\
& Female & $4,594 / 5,435(84 \%)$ & $2,764 / 3,623(76 \%)$ & \\
& $1^{\text {st }}(7 \mathrm{AM}-3 \mathrm{PM})$ & $3,039 / 5,435(56 \%)$ & $1,433 / 3,623(40 \%)$ & \\
By Shifts & $2^{\text {nd }}(3 \mathrm{PM}-11 \mathrm{PM})$ & $322 / 5,435(6 \%)$ & $3,56 / 3,623(10 \%)$ & \\
& $3^{\text {rd }}(11 \mathrm{PM}-7 \mathrm{AM})$ & $279 / 5,435(5 \%)$ & $3,27 / 3,623(9 \%)$ & \\
& $4^{\text {th }}($ Registry and any 12 Hour Shift) & $1,795 / 5,435(33 \%)$ & $1,507 / 3,623(41 \%)$ & \\
Age Groups & $18-34$ & $1,487 / 5,435(28 \%)$ & NA & \\
(non-participant age & $35-44$ & $1,258 / 5,435(23 \%)$ & NA & \\
data unavailable) & $45-54$ & $1,395 / 5,435(26 \%)$ & NA & \\
& $55-64$ & $1,128 / 5,435(21 \%)$ & NA & \\
& 65 and + & $167 / 5,435(3 \%)$ & NA & \\
\hline
\end{tabular}

\subsection{Impact: utilization of preventive services after one year}

We examined trends regarding utilization of services, screening, preventive visits and programs over time. Review of our medical claims data at one year revealed an important increase in preventive care visits over the previous year (see Table 2).

\subsection{Outcomes}

A review of medical claims for the time period of the study revealed a desired shift in health resources utilization, early detection and reduction in healthcare gaps as shown in Table 3.
Table 2. Preventive care visits, participation rates by gender

\begin{tabular}{lll}
\hline & Year 1 & Year 2 \\
\hline Male & $244 / 841(29 \%)$ & $580 / 841(69 \%)$ \\
Female & $2,573 / 4,594(56 \%)$ & $3,767 / 4,594(82 \%)$ \\
\hline
\end{tabular}

Table 3 reveals an increase in the number of prescriptions by participants. Although the precise reason for this is unknown, it is possible that previously untreated medical conditions were being treated after the primary care physician visit. There was additionally an increase in the percentage of prescriptions written for generic drugs for participants compared with non participants. Based on medical claims, it was estimated that at baseline $30 \%$ of employees saw a physician 
regularly and 2,900 health conditions were not adequately treated. Analysis of the relative CGI - a measure of compliance with medical standards per condition in relation to the population, revealed that the medical adherence was higher in participants compared with non-participants. Of note, the number of employees with $\$ 0$ (receiving no care recorded in the system) was reduced in half compared to the previous year.

Table 3. Outcome indicators after 1 year

\begin{tabular}{lll}
\hline Indicators & $\begin{array}{l}\text { Participant \% } \\
\text { Change }\end{array}$ & $\begin{array}{l}\text { Non-Participant } \\
\text { \% Change }\end{array}$ \\
\hline Preventive Office Visits & $+35 \%$ & $+3 \%$ \\
Scripts/1,000 & $+5 \%$ & $+1 \%$ \\
Generic Prescriptions/1,000 & $+11 \%$ & $+6 \%$ \\
\% of Members with \$0 Claims & $-55 \%$ & $+12 \%$ \\
Relative Compliance Gap Index & $-7 \%$ & $+18 \%$ \\
Overall Emergency Room Use & $-5 \%$ & $-6 \%$ \\
\hline
\end{tabular}

\section{Discussion}

This study represents an important contribution to the emerging literature focused on strategies designed to improve the health of the employee workforce this study sought to evaluate initial outcomes of an employer based wellness program operating in collaboration with a primary care physician network. While the ability to capture data in the manner captured in this study may not be generalizable to all settings outside of healthcare, the importance of primary care and prevention in the overall health of the population is an important tenet of the ACA and is an important consideration for long term success. ${ }^{[10,13]}$ The approach described in this paper was tested in the context of a workplace health promotion program that operated as a complement to the work of primary care physician and medical home- providing incentives to adhere to recommended care and supplemental programming designed to promote improved health outcomes for those with medical risk factors.

The strengths of this study include the large sample size, physician verified HRA data, biometrics, and medical claims data. We additionally had the ability to evaluate progress of participants over time. The primary limitation of this study is the lack of information on absenteeism, the inability to document activity of participants in programs that were not subsidized and the limited involvement of participants in intensive interventions in this initial time period, limitations that are shared with other reports in the literature.

The population of this healthcare organization was largely female. The participation rates of males was lower than that of the females, a factor which cannot be directly explained by this study but themes that emerged during early focus groups included concern that participation might affect employment status, lack of time to participate and lack of interest. Emphasizing the separation of the program from employment decisions, engagement of wellness champions, managers, and adjustment of incentives are examples of a few of the approaches used to address these concerns. ${ }^{[14]}$

Not all worksite wellness programs demonstrate lower costs and preventable utilization. The discrepancies may be due to the definition of a wellness program, difference in participation rates, intervention intensity or program implementation or precision of data used in evaluation..$^{[4,15-17]}$

Given the paucity of data in the peer reviewed literature describing comprehensive worksite wellness programs, this paper adds additional support to the concept of testing population health management strategies in employee populations in which a range of data inputs are available to evaluate outcomes.

Despite the limitations of this study, we demonstrated the ability to engage a large percentage of the employed population across multiple sites in the context of a 24 hour work force in one year. Medical claims data revealed a desired shift in health resources utilization, early detection and reduction in healthcare gaps. The important elements we describe which included incentivizing establishment of a medical home, nurse navigation and provisions of resources to support those with medical risks allowed assessment of population health risks and reduction of barriers to care. Preliminary results show a high level of engagement, a shift in healthcare spending towards preventive care, generic medication usage, and a reduction in avoidable care costs.

The implications for health promotion practice or research are that it is feasible to engage a large percentage of employees in a multi-site setting to encourage preventive screening and primary care physician visits. This represented a first step for many individuals in recognizing their health risks and receiving assistance in developing strategies to optimize their health. While financial incentives were incorporated in this strategy, it was not the sole focus of the program. In addition, the activities discussed in this paper were conducted in the context of the adoption of institutional strategies to promote wellness and improvements in access to primary care, and the availability of low cost healthy food. Other activities included team challenges, social support, reward and recognition.

\section{Conclusions}

This study represents an important contribution to the emerging literature on strategies designed to improve the health of the employee work force by promoting the establishment of 
medical home and navigate employee to available resources. A more complete picture of employee wellness initiatives can be gained by inclusion of evaluation of claims, biometric and HRA data. Programs focused on outcomes achieved with incentivizing use of primary care have a high potential for success, however future studies evaluating outcomes of participants with chronic conditions and evaluation of indirect costs such as absenteeism will provide a more comprehensive view of overall impact.

\section{REFERENCES}

[1] Centers for Disease Control and Prevention. Chronic diseases: the power to prevent, the call to control, at-a-glance 2009. Atlanta, GA: U.S. Department of Health and Human Services. Rev Publ Health. 2008; 29: 303-23.

[2] National Center for Chronic Disease prevention and Health Promotion. The Power of Prevention Chronic disease. The public health challenge of the $21^{\text {st }}$ century. Atlanta, GA: Retrieved 9/25/15. Available from: http://www.cdc.gov/chronicdisease/pdf/2 009-Power-of-Prevention.pdf

[3] Osilla KC, Van Busum L, Scjmuer C, et al. Systematic Review of the Impact of Worksite Wellness Programs. Am J Manag Care. 2012; 18(2): e68-e81. PMid: 22435887.

[4] Mattke S, Schnyer C, Van Busum KR. A Review of the U.S. Workplace Wellness Market. RAND Cooperation. 2012. Retrieved 9/25/15. Available from: http://www.rand.org/pubs/occasional_pap ers/OP373.html

[5] Available from: http://www.dol.gov/ebsa/newsroom/fswe llnessprogram.html

[6] Haisley E, Volpp KG, Pellathy T, et al. The impact of alternative incentive schemes on completion of health risk assessments Am J of Health Promot. 2011; 26(3): 184-188. PMid: 22208418. http://dx.doi.org/10.4278/ajhp.100729-ARB-257

[7] O’Donnell M. Does Workplace Health Promotion Work or Not? Are You Sure You Really Want to Know the Truth? Am J Health Promot. Sept/Oct 2013; 28(1): iv-vii. http://dx.doi.org/10.4278/ajh p.28.1.iv

[8] Available from: http://www.ncqa.org/HEDISQualityMeasu rement. aspx. Retrieved 9/25/15.

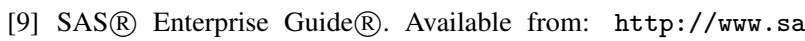
s.com/en_us/software/enterprise-guide.html. Retrieved 9/25/15.
[10] Terry PE, Seaverson ELD, Grossmeier J, et al. Association Between Nine Quality Components and Superior Worksite Health Management Program Results. J Occup Environ Med. 2008; 50(6): 633-41. PMid: 18545090. http://dx.doi.org/10.1097/J0M.0b013e3 $1817 \mathrm{e} 7 \mathrm{c} 1 \mathrm{c}$

[11] Grossmeier J, Terry PE, Cipriotti A, et al. Best Practices in Evaluating Worksite Health Promotion Programs. Am J Health Promot. 2010; 24(3): 1-12. http://dx.doi.org/10.4278/ajhp.24.3.TAHP

[12] Employee Benefits Security Administration. FAQs about the HIPAA Nondiscrimination Requirements. Washington, DC: U.S. Department of Labor; 2013. Retrieved 9/25/15. Available from: http: //www.dol.gov/ebsa/faqs/faq_hipaa_ND.html

[13] Starfield B, Shi L, Macinko J. Contribution of Primary Care to Health Systems and Health. Milbank Q. 2005; 83(3): 457-502. PMid: 16202000. http://dx.doi.org/10.1111/j.1468-0009. 2005.00409. $\mathrm{x}$

[14] Seaverson ELD, Grossmeier J, Miller TM, et al. The Role of Incentive Design, Incentive Value, Communications Strategy, and Worksite Culture on Health Risk Assessment Participation. Am J Health Promot. May/June 2009; 23(5): 343-352.

[15] Aldana SG, Merrill RM, Price K, et al. Financial impact of a comprehensive multisite workplace health promotion program. Prev Med. 2005 Feb; 40(2): 131-137.

[16] Baicker K, Cutler D, Song Z. Workplace wellness programs can generate savings. Health Affairs. 2010; 29(2): 304-311. PMid: 20075081. http://dx.doi.org/10.1377/hlthaff .2009.0626

[17] Goetzel RZ, Ozminkowski RJ. The health and cost benefits of work site health-promotion programs. Annu Rev Publ Health. 2008; 29: 303-23. PMid: 18173386. http://dx.doi.org/10.1146/annur ev.publhealth.29.020907.090930 